\title{
Diabetic Macular Edema Estimation Using Slit Lamp Biomicroscopy Versus That Using Oct
}

\author{
Trisha Sharma, Susan DSouza, Manjunath Kamath \\ Manipal University, India
}

\begin{abstract}
Purpose: Comparison of Diabetic macular edema estimation using slit lamp biomicroscopy versus that using OCT.

Materials and Methods: We performed a retrospective analysis of 121 patients (154 eyes) with established Type 2 diabetes mellitus, divided into three groups. Group I consisted of 62 eyes with NPDR, Group II, 27 eyes with PDR and Group III, 66 eyes with CSME. Diagnosis of CSME was made as per ETDRS protocol, using slit lamp stereoscopic biomicroscopy. DME was defined on OCT as central foveal thickness greater than $250 \mu \mathrm{m}$. OCT scanning was performed through the macula of each eye after pupillary dilatation.

Results: The mean age of patients included was $60.70 \pm 9.20$ years and $61.98 \%$ were males. Only 66 eyes were classified as having DME clinically as opposed to 109 eyes by OCT, leading to a significant sub-estimation of $39.44 \%$ eyes. The mean macular thickness in the CSME patients identified by slit lamp biomicroscopy was $399.59 \pm 105.31 \mu \mathrm{m}$. The mean central macular thickness in the sub-estimated cases was $290.58 \pm 28.92 \mu$ m overall, $290.10 \pm 26.19 \mu \mathrm{m}$ in the PDR group and $290.95 \pm 31.46 \mu \mathrm{m}$ amongst NPDR patients.

Conclusion: Mild macular thickening on OCT may not correspond to overt edema clinically and has been termed sub-clinical macular edema by some authors. We report a subestimation of DME in $39.44 \%$ eyes in our study. The emerging importance of monitoring of these vulnerable patients and early detection of their conversion to overt CSME must be realised. In conclusion, assessment of diabetic macular edema with OCT is probably more objective and reliable.
\end{abstract}

Keywords: Diabetic Macular Edema, OCT, Slit lamp biomicroscopy, subestimation, CSME

\section{Introduction}

Officially crowned as The diabetes capital of the world, India houses a massive 62 million diabetics, making every fifth diabetic in the world, an Indian. ${ }^{1-3}$ Out of these, $34.6 \%$ are ,estimated to have diabetic retinopathy. ${ }^{4-7}$ It is fast gaining the status of the number one cause of avoidable blindness all over the world and this, amongst the working population of any nation, takes a heavy toll on its social and economic productivity. Macular edema is the leading cause of visual impairment in patients with diabetic retinopathy and its importance as a major public health issue is gaining recognition.-12 It can develop at any stage of diabetes and there are various factors that determine the visual outcome in these cases, including central foveal involvement, perifoveal capillary blood flow velocity,capillary occlusion in the foveal zone and central foveal thickness. ${ }^{13,14}$ Hence, there is an urgent need for early detection, regular monitoring and timely treatment of macular edema in these vulnerable patients.

Correspondence: Trisha Sharma

E-mail: trishu doc@yahoo.co.in 
As the traditional methods of assessment of macular thickening evolved from slit lamp biomicroscopy to conventional stereo fundus photography, these methods remained both largely subjective as well as relatively imperceptive to small changes in retinal thickness. Thus, there was continued scouting for newer, better techniques to quantify retinal thickness. ${ }^{15}$

Optical Coherence Tomography is an objective, non-invasive technique that has been widely used over the past two decades and has proved invaluable in the diagnosis and evaluation of several macular conditions such as Central Serous Chorioretinopathy, clinically significant diabetic macular edema (CSME), cystoid macular edema, epiretinal membranes, and macular holes. ${ }^{16-18}$ It has undergone several modifications over time, to emerge as a highly reproducible, patient friendly diagnostic imaging technology. It generates real time, high resolution cross sectional tomographic images and operates on the principle of low coherence interferometry. Past studies on patients with diabetic retinopathy uphold that central foveal thickness determined using OCT equate well with visual acuity and has proved to be a valuable asset in monitoring of macular thickening pre and post laser therapy. ${ }^{18-20}$ As per the current established protocol by ETDRS, the decision of using focal laser photocoagulation for clinically significant macular edema (CSME) relies solely on the subjective presence or absence of macular thickening by slitlamp fundus stereo biomicroscopy. ${ }^{21}$ But, lately OCT has come to assume a pivotal role in the assessment of diabetic macular edema and is deemed to be more objective and reliable. However, it is imperative that we evaluate whether the retinal thickness measurements generated by OCT are in concordance with the subjective assessment by the traditional techniques. ${ }^{22}$ We also need to evaluate whether the use of an OCT will aid in greater accuracy of establishing diabetic macular edema as opposed to the standard techniques in use.

In this study, we seek to compare estimation of Diabetic macular edema using slit lamp biomicroscopy with that using Cirrus SD OCT.

\section{Methods}

A retrospective analysis of data of 121 patients (154 eyes) was obtained from the records of all diabetic patients who visited our outpatient clinic between January 2012 to May 2014. The inclusion criteria was any established case of diabetes mellitus, between 40 and 80 years, diagnosed to have diabetic retinopathy. Diabetes was established by physician diagnosis, laboratory reports and treatment history. Patients with significant media opacities that would hinder with OCT signal and those with pre existing macular pathologies like epiretinal membrane, macular hole or ARMD changes as well as other causes of macular edema were excluded from the study. Clearance was obtained from Institutional Ethics Committee.

All cases identified were further divided into three groups. Group I with 61 eyes having Non proliferative diabetic retinopathy, Group II consisting of 27 eyes with Proliferative diabetic retinopathy and Group III included 66 eyes with clinically significant macular edema. Diagnosis of CSME was made using slit lamp stereoscopic biomicroscopy by an experienced ophthalmologist. Clinically Significant 
Macular Edema was defined as per the Early-Treatment Diabetic Retinopathy Study (ETDRS) protocol ${ }^{23}$ as presence of retinal thickening or hard exudates associated with adjacent retinal thickening within $500 \mu \mathrm{m}$ of the center of the fovea or zone of retinal thickening 1 disc diameter or larger, any part of which lies within 1 disc diameter of the center of the macula. Diabetic Macular Edema was defined on OCT as central foveal thickness greater than $250 \mu \mathrm{m} .{ }^{24,25} \mathrm{OCT}$ scanning was performed for each eye after pupillary dilatation using tropicamide $1 \%$ and phenylephrine hydrochloride $2.5 \%$ eyedrops, by a single ,experienced ophthalmologist.

OCT works on the principle of low coherence interferometry that analyses the time delay of light reflected from various retinal microstructures located at various depths and generates a high resolution image. We used a widely available Carl Zeiss SD-OCT unit in our study.

The Central Foveal Thickness (CFT) considered here was the average thickness of retina within the central $1 \mathrm{~mm}$ area, marked at the point of intersection of six radial scans, procured using the fast macular thickness map protocol and an automated value was displayed by the OCT machine using the retinal map analysis function.

Descriptive statistical methods (mean, standard deviation) as well as two sample, two sided students unpaired ' $t$ ' test, a statistical package SPSS version 17.0 was used to do the statistical analysis and $p$ value $<0.05$ was considered as significant.

\section{Results}

The mean age of patients included was $60.70 \pm 9.20$ years and $61.98 \%$ were males. Only 66 eyes were classified as having DME clinically as opposed to 109 eyes by OCT, leading to a significant sub-estimation of $39.44 \%$ eyes.

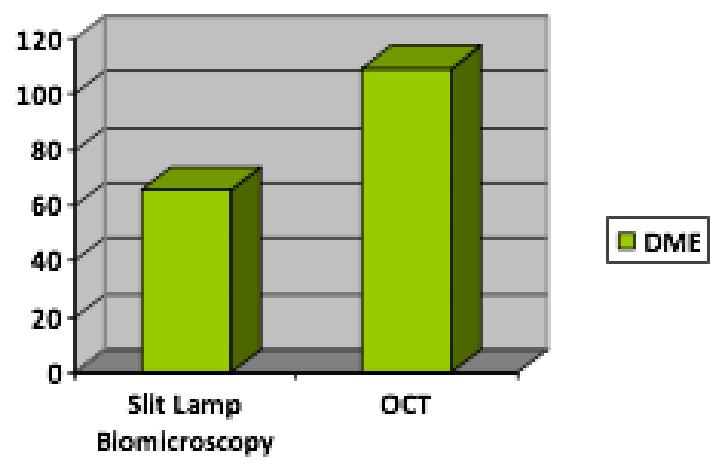

Fig. 1. The number of patients classified as DME by Slit lamp biomicroscopy Vs that by OCT.

Out of these sub-estimated 43 eyes, diagnosed as DME by OCT, $24(55.81 \%)$ had NPDR and 19 (44.18\%) had PDR. The mean macular thickness in the CSME patients identified by slit lamp biomicroscopy was $399.59 \pm 105.31 \mu \mathrm{m}$ while those identified by OCT was $356.58 \pm 99.32 \mu \mathrm{m}$. 


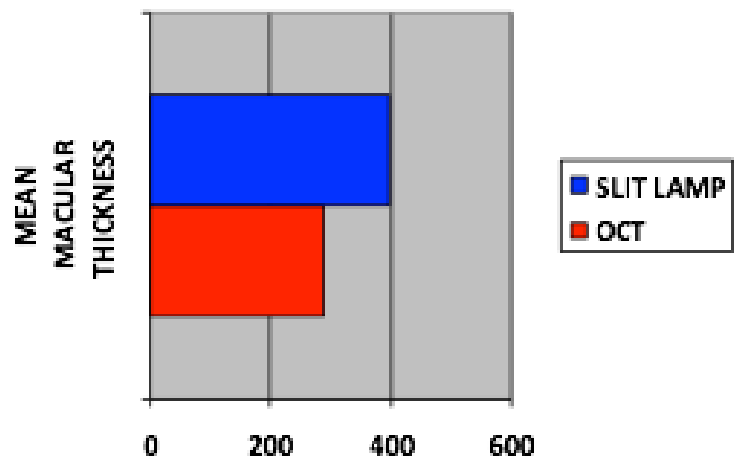

Fig. 2. As is evident, a much higher macular thickness is required to be recognised as DME by slit lamp biomicroscopy as opposed to OCT.

This was found to be statistically significant at $\mathrm{p}=0.007(\mathrm{p}<0.05, \mathrm{Cl}$ at $95 \%$ ). The mean central macular thickness in the sub-estimated cases was $290.58 \pm 28.92 \mu \mathrm{m}$ overall, $290.10 \pm 26.19 \mu \mathrm{m}$ in the PDR group and 290.95 $\pm 31.46 \mu \mathrm{m}$ amongst NPDR patients.

\section{Discussion}

All subjects, in whom retinal thickening or hard exudates were observed at the macula during slit lamp biomicroscopy, also exhibited a corresponding increase in macular thickness on OCT. However, there were instances when OCT detected macular thickening in the absence of any clinically detectable macular edema.
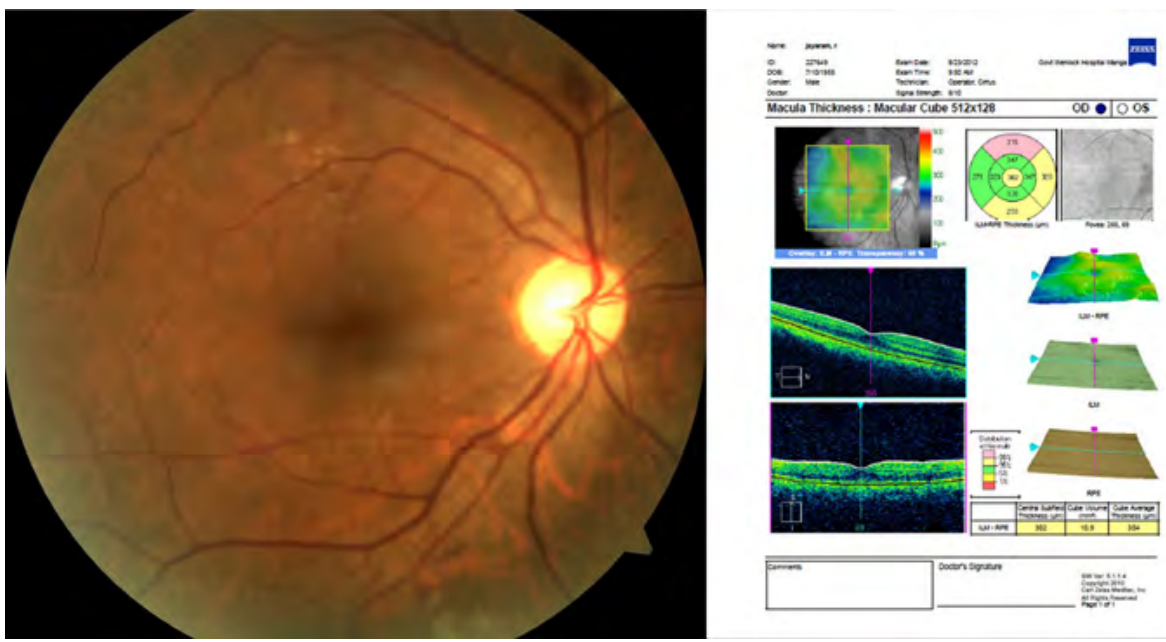

This was perhaps more common when the type of edema was diffuse rather than focal or when there were no tell-tale hard exudates. We found that the central foveal thickness had to be substantially greater to be clinically identified as CSME. The 
mean macular thickness in the CSME patients identified by slit lamp biomicroscopy was $399.59 \pm 105.31 \mu \mathrm{m}$ while those identified by OCT was $356.58 \pm 99.32 \mu \mathrm{m}$. This difference was found to be statistically significant with $p$ value $<0.05$. This led to a significant sub-estimation of $39.44 \%$ eyes by slit lamp biomicroscopy as opposed to that by OCT.
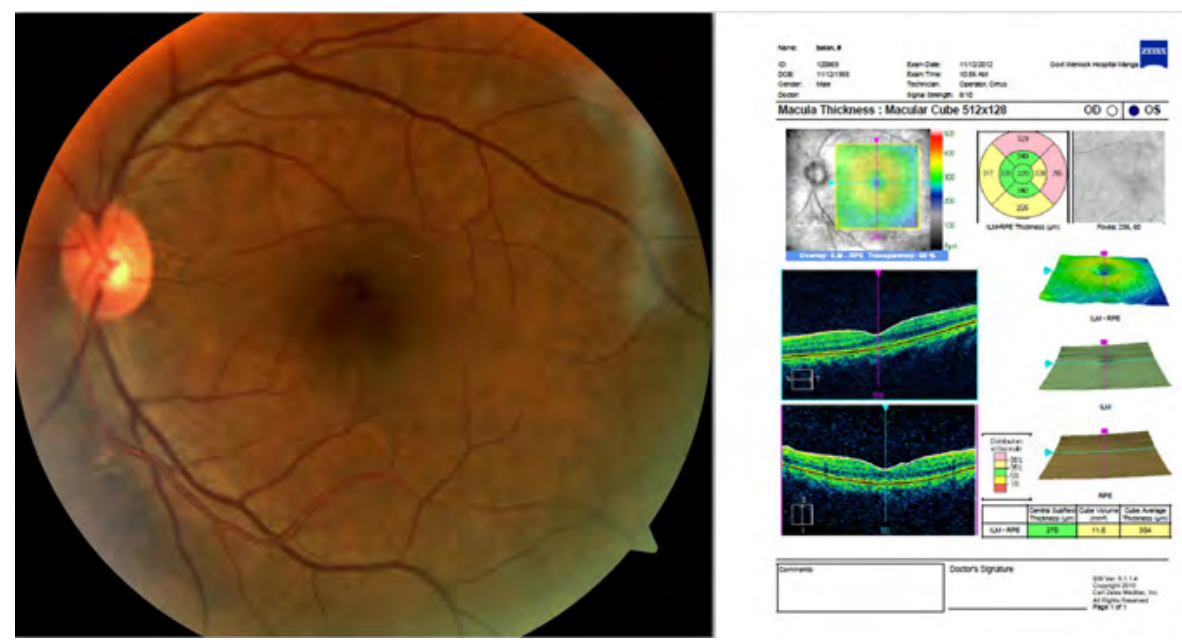

A similar study conducted by Koleva-Georgieva in 2010, evaluating the role of OCT in detecting early macular edema in diabetics, shared the same observations. ${ }^{26}$ Such cases have been described in the past as sub-clinical DME. ${ }^{27,28}$ The term was coined by Brown who reported up to $25 \%$ of subclinical cases. ${ }^{27}$ In another study by Browning, 58 to $90 \%$ of cases were found to be sub-estimated. ${ }^{29}$ Bhavsar and Subramaniam reported an interesting observation that a sizeable number of subjects with subclinical macular edema eventually progressed to CSME as compared to the control popuation. ${ }^{28}$

It has been previously reported that while all three standard methods of slitlamp biomicroscopy, fluorescein angiography and OCT have been found to be complementary for diagnostic purposes, OCT is a more objective and less invasive technique for follow up of diabetic macular edema. ${ }^{30}$

There have been several studies by Udaondo et al., ${ }^{31}$ Song et al., ${ }^{32}$ Takatsuna et al..$^{33}$ and Vemala et al..$^{34}$ that have explored the utility of OCT in various dimensions of macular edema such as comparison with Indirect ophthalmoscopy in diagnosis of DME, monitoring the efficacy of new innovative treatment for BRVO by following macular edema with OCT and exploring the various levels of efficacies of intravitreal triamcinolone, bevacizumab and laser photocoagulation as treatment for DME. However, very little attention has been paid to the new concept of predicting susceptibility to CSME in patients, early detection of DME in them as well as comparison with the standard subjective methods of evaluation that are still the protocol.

Limitation of our study is lack of records of other parameters due to retrospective 
collection of data. There are many more parameters that can be analysed and their respective relationship with macular thickness can be explored, like visual acuity, $\mathrm{HbA1C}$ levels, duration of diabetes etc. Also, we didn't draw comparisons with healthy subjects or a baseline control group.

In conclusion, we found that OCT was a useful and sensitive technique for quantitative measurement of retinal thickness in patients with diabetes. Our study fully supports previous suggestions that early changes in retinal thickness can be detected by OCT despite normal findings in slit lamp biomicroscopy, thus facilitating early detection and timely management of such patients.

\section{References}

1. Kumar A, Goel MK, Jain RB, Khanna P, Chaudhary V. India towards diabetes control: Key issues. AMJ 2013; 6: 524-531.

2. Kaveeshwar SA, Cornwall J. The current state of diabetes mellitus in India. AMJ 2014; 7: 45-48

3. Joshi S, Joshi SR, Mohan V. Methodology and feasibility of a structured education program for diabetes education in India: The National Diabetes Educator Program. Indian J Endocrinol Metab. 2013; 17: 396-401

4. Yau JW, Rogers SL,Kawasaki R, Lamoureux EL, Kowalski JW, Bek T et al. Meta-Analysis for Eye Disease (META-EYE) Study Group. Global prevalence and major risk factors of diabetic retinopathy. Diabetes Care 2012; 35: 556-564

5. Namperumalsamy P, Kim R, Vignesh TP, Nithya N, Royes J, Gijo T et al. Prevalence and risk factors for diabetic retinopathy: a population-based assessment from Theni District, south India. Br J Ophthalmol 2009; 93:429-434

6. Dandona L, Dandona R, Naduvilath TJ, McCarty CA, Rao GN. Population based assessment of diabetic retinopathy in an urban population in southern India. Br J Ophthalmol 1999; 83:937-940

7. Raman R, Rani PK, Reddi Rachepalle S, Gnanamoorthy P, Uthra S, Kumaramanickavel G et al. Prevalence of diabetic retinopathy in India: Sankara Nethralaya Diabetic Retinopathy Epidemiology and Molecular Genetics Study report 2. Ophthalmology2009; 116:311-318

8. Nicholson BP, Schachat AP.A review of clinical trials of anti-VEGF agents for diabetic retinopathy. Graefes Arch Clin Exp Ophthalmol 2010; 248: 915-930

9. Klein R, Klein BEK, Moss SE. Visual impairment in diabetes. Ophthalmology 1984; 91: 1-9

10. Soheilian M, Garfami KH, Ramezani A, Yaseri M, Peyman GA. Two-year results of a randomized trial of intravitreal bevacizumab alone or combined with triamcinolone versus laser in diabetic macular edema. Retina 2012; 32:314-321.

11. Klein R, Klein BEK, Moss SE. The Wisconsin epidemiologic study of diabetic retinopathy. IV. Diabetic macular edema. Ophthalmology 1984; 91: 1464-1474

12. Gillies MC, Islam FMA, Zhu M, Larsson J, Wong TY.Br J Ophthalmol. Oct 2007; 91: 1323-26.

13. Gardner TW, Larsen M, Girach A, Zhi X: Protein Kinase C Diabetic Retinopathy Study (PKC-DRS2) Study Group. Diabetic macular oedema and visual loss: relationship to location, severity and duration. Acta Ophthalmol 2009, 87:709-713.

14. Sakata K, Funatsu H, Harino S, Noma H, Hori S: Relationship of macular microcirculation and retinal thickness with visual acuity in diabetic macular edema. Ophthalmology 2007, 114:2061-2069.

15. Nussenblat RB, Kaufman SC, Palestine AG, Davis MD, Ferris FL. Macular thickening and visual acuity. Ophthalmology 1987; 94:1134-1139.

16. Hee MR, Izatt JA, Swanson EA, Huang D, Schuman JS, Lin CP et al. Optical coherence tomography of the human retina. Arch Ophthalmol. 1995; 113:325-332.

17. Puliafito CA, Hee MR, Lin CP, Reichel E, Schuman JS, Duker JS et al. Imaging of macular diseases with optical coherence tomography. Ophthalmology. 1995; 102:217-229.

18. Hee MR, Puliafito CA, Duker JS, Reichel E, Coker JG, Wilkins JR et al. Topography of diabetic macular edema with optical coherence tomography. Ophthalmology 1998; 105:360-370

19. Hee MR, Puliafito CA, Wong C, Duker JS, Reichel E, Rutledge B et al. Quantitative assessment of macular edema with optical coherence tomography. Arch Ophthalmol. 1995; 113: 1019-1029. 
20. Otani T, Kishi S, Maruyama Y. Patterns of diabetic macular edema with optical coherence tomography. Am J Ophthalmol. 1999; 127: 688-693.

21. Early Treatment Diabetic Retinopathy Study Research Group. Photocoagulation for diabetic macular edema: early treatment diabetic retinopathy study report number 1 . Arch Ophthalmol 1985; 103:1796-1806

22. Strom C, Sander B, Larsen N, Larsen M, Lund-Andersen H. Diabetic Macular Edema Assessed with Optical Coherence Tomography and Stereo Fundus Photography Invest. Ophthalmol. Vis. Sci. $2002 ; 43: 241-245$

23. Early Treatment Diabetic Retinopathy Study Research Group. ETDRS report number 7: Early Treatment Diabetic Retinopathy Study design and baseline patient characteristics. Ophthalmology 1991; 98:741-756.

24. Chan CKM ,Mohamed S, Shanmugam MP, Tsang CW, Lai TYY, D Lam DSC. Decreasing efficacy of repeated intravitreal triamcinolone injections in diabetic macular oedema.Br J Ophthalmol .2006; 90:1137-1141.

25. Davis MD, Bressler SB, Aiello LP,3 Bressler NM, Browning DJ, Flaxel CJ.Comparison of Time-Domain OCT and Fundus Photographic Assessments of Retinal Thickening in Eyes with Diabetic Macular Edema. Invest Ophthalmol Vis Sci.2008; 49: 1745-1752.

26. Koleva-Georgieva DN, Sivkova NP. Optical coherence tomography for the detection of early macular edema in diabetic patients with retinopathy. Folia Med Plovdiv; 52: 40-48.

27. Brown JC, Solomon SD, Bressler SB, Schachat AP, Di Bernardo C, Bressler NM. Detection of diabetic foveal edema: Contact lens biomicroscopy compared with optical coherence tomography. Arch Ophthalmol. 2004. 122: 330-335.

28. Bhavsar KV, Subramanian ML. Risk factors for progression of subclinical diabetic macular oedema. Br J Ophthalmol. 2011; 95(5): 671-674.

29. Browning DJ, McOwen MD, Bowen RM Jr, O'Marah TL. Comparison of the clinical diagnosis of diabetic macular edema with diagnosis by optical coherence tomography. Ophthalmology 2004 ;111: 712-715.

30. Baskin DE. Optical coherence tomography in diabetic macular edema. Curr Opin Ophthalmol. 2010; 21: 172-177.

31. Udaondo P, Diaz-Llopis M, Garcia-Delpech S, Salom D, Romero J. Intravitreal plasmin without vitrectomy for macular edema secondary to branch retinal vein occlusion. Arch Ophthalmol .2011; 129:283-287.

32. Song JH, Lee JJ,Lee SJ. Comparison of the short-term effects of intravitreal triamcinolone acetonide and bevacizumab injection for diabetic macular edema. KJO 2011; 25:156-160

33. Takatsuna Y, Yamamoto S, Nakamura Y, Tatsumi T, Arai M, Mitamura Y. Long-term therapeutic efficacy of the subthreshold micropulse diode laser photocoagulation for diabetic macular edema. Jpn J Ophthalmol. 2011; 55:365-369

34. Vemala R, Koshy S, Sivaprasad S. Qualitative and quantitative OCT response of diffuse diabetic macular oedema to macular laser photocoagulation. Eye 2011; 25:901-908 